УДК 33

DOI $10.21661 / r-529989$

\title{
I.B. Лonama
}

\section{БУХГАЛТЕРСКИЙ УЧЕТ И КАЛЬКУЛИРОВАНИЕ СЕБЕСТОИМОСТИ В СТРАХОВЫХ ОРГАНИЗАЦИЯХ}

Аннотация: рост рынка страхования является одним из ключевых условий обеспечения развития экономики и социальной сферы страны, что обусловливает важность совершенствования страховой деятельности. В статье рассмотрены вопросы, касающиеся оптимизаџии бухгалтерского учета в страховых компаниях. Автор, исследуя существующие практики, приходит к выводуо необходимости создания эффективных стандартов учета.

Ключевые слова: страховая деятельность, страховая компания, бухгалтерский учет, себестоимость продукиии, калькулирование себестоимости, формирование расходов.

\section{P.V. Lopata}

\section{ACCOUNTING AND COSTING IN INSURANCE COMPANIES}

Abstract: the growth of the insurance market is one of the most important conditions for the country's social and economic development. The article discusses issues related to the optimization of accounting in insurance companies. It is suggested that the existing accounting standards should be improved.

Keywords: insurance, insurance company, accounting, cost price, costing, expenditure accounting.

С усилением глобализационных и интеграционных процессов в мире, развитием компьютерно-информационных технологий страхование является незаменимым механизмом для поддержания цикличности воспроизводственного процесса, обеспечения социальной стабильности, безопасности и уверенности в завтрашнем дне. Также страхование можно рассматривать и как перспективный вид бизнеса, то есть как деятельность, приносящую прибыль. При взвешенной 
государственной политике, являющейся источником наполнения государственного бюджета, страхование - ведущая отрасль финансово-кредитной системы, способная обеспечить устойчивое социально-экономическое развитие.

В условиях конкуренции и осложнения бизнес-процессов, когда компания стремительно развивается в динамичной внешней среде, четкость, взвешенность, обоснованность управленческих решений по любым аспектам деятельности, приобретает особое значение, особенно с точки зрения использования дефицитных ресурсов для реализации определенной стратегии. Решение о расширении сфер деятельности, реализации новых проектов особенно важны, поскольку могут привести компанию к укреплению конкурентной позиции, или аннулировать все ее предыдущие усилия. В связи с этим возникает вопрос об информационном обеспечении процесса принятия управленческих решений, формировании доказательной базы, на которой бы основывались данные решения.

Одним из аспектов обоснования и поддержки решений по расширению сфер и объемов деятельности, по выводу новых продуктов на рынок является планирование расходов, которые могут быть понесены в результате принятия правильного решения с целью определения требуемого уровня доходности нового направления деятельности или продукта. Вопрос способа расчета таких затрат и калькуляции себестоимости остается. Особенно важным вопрос видится в сфере услуг, где уровень косвенных расходов является значительным, что требует выбора способа их отнесения конкретную услугу. Одним из инструментов бухгалтерского учета, позволяющего решить вопрос распределения косвенных (накладных) расходов является процессный подход к калькуляции себестоимости услуги. Он предусматривает распределение косвенных расходов на услуги путем их первоочередного распределения на процессы, обеспечивающие создание этой услуги.

Актуальность изучаемой темы также определяется тем, что государственный регулятор деятельности страховых организаций (Центральный банк РФ) повысил требования к эффективности учетного процесса в страховании. Для некредитных организаций в 2017 были разработаны новые отраслевые стандарты 
учета, введен новый план счетов, учетная политика приближена к требованиям МСФО.

Согласно ПБУ 10/99 «Расходы организации», расходами организации признается уменьшение экономических выгод в результате выбытия активов и (или) возникновения обязательств, приводящее к уменьшению капитала [1].

Сведения о расходах в организации необходимы, в первую очередь, руководителю предприятия и его подразделений, а также участникам производственного процесса в целях определения политики управления предприятием, направленной на снижение издержек и увеличение прибыли.

В процессе сбора информации, необходимой для принятия производственных решений, следует исходить из того, что определенный вид затрат может обладать важностью для одного типа решений, но не может учитываться для другого. В действительности производственные затраты имеют достаточно широкий перечень классификационных признаков.

Себестоимость продукции, являясь затратами предприятия на производство и обращение, выступает в качестве основы соизмерения расходов и доходов, то есть самоокупаемости, представляющей собой основополагающий признак рыночного хозяйственного расчета. Себестоимость является одним из обобщающих показателей эффективности и интенсификации использования ресурсов [2].

В целом, анализ себестоимости продукции призван выявлять возможности увеличения эффективности применения материальных, денежных и трудовых ресурсов в производственном процессе, в снабжении и сбыте продукции. Оценка себестоимости продукции способствует более правильной оценке уровня показателей прибыли и рентабельности, достигнутого предприятиями [3, с.78].

Выделяют следующие критерии классификации себестоимости выпускаемой продукции (работ, услуг):

- по способу получения себестоимость разделяется на:

а) плановую (нормативную), разработанную на основе прогрессивных норм и экономических нормативов за отчетный период; 
б) фактическую (отчетную), определенную на основе данных бухгалтерского учета по истечении отчетного периода и представляющую собой достоверную информацию о фактических затратах на производство продукции;

- по объему учета затрат себестоимость разделяется на:

а) себестоимость производства готовой продукции, включающую в себя прямые и накладные затраты производства;

б) себестоимость реализованной (отгруженной) продукции, объединяющую производственную себестоимость продукции и расходы по ее реализации (коммерческие, административно-хозяйственные);

- по степени обобщения себестоимость разделяется на:

а) удельную себестоимость, представляющую собой себестоимость в расчете на единицу произведенной продукции каждого вида;

б) сводную себестоимость, представляющую собой общую сумму затрат на весь объем произведенной продукции и рассчитанную по следующим группировкам: на весь объем, на спецификацию, на клиента.

Структура себестоимости продукции, работ, услуг включает в себя основные группы расходов [4, с. 71]:

- прямые расходы;

- накладные расходы.

Прямые затраты связаны с производством конкретной продукции и полностью относятся на ее себестоимость.

Накладные затраты связаны с производством некоторого перечня продукции и распределяются на каждый из видов пропорционально прямым затратам.

Производственные затраты связаны с осуществлением производственной деятельности, в процессе которой формируется производственная себестоимость выпущенной и реализованной продукции;

Непроизводственные затраты - затраты, не включаемые в производственную себестоимость продукции и состоящие из административно-хозяйственных и коммерческих расходов. 
При составлении калькуляции себестоимости продукции допускается коммерческие и административно-хозяйственные расходы не раскрывать на составные части, а показывать общей суммой ввиду того, что они являются накладными и распределяются пропорционально определенной базе распределения. Основу указанных затрат составляют структурные подразделения, отнесенные к соответствующему месту учета затрат, определенному для целей управленческого учета [16, с. 73].

В условиях отсутствия специально разработанных стандартов для страховых компаний по учетным аспектам отдельных объектов (в том числе расходов) и требований, которые предусматривали неприменение ими ПБУ 10/99, этот нормативный документ продолжает использоваться.

По действующему стандарту себестоимость выполненных услуг состоит из расходов, прямо связанных с предоставлением таких услуг, а именно [5, с. 70]:

- прямые материальные расходы;

- прямые расходы на оплату труда;

- амортизация производственных основных средств и нематериальных активов, связанных с оказанием услуг;

- общепроизводственные расходы, которые относятся на себестоимость изготовленных и реализованных услуг в соответствии с ПБУ;

- стоимость приобретенных услуг, прямо связанных с оказанием услуг;

- прочие прямые затраты, включая затраты по закупке электроэнергии.

Расходы, формирующие себестоимость предоставленных услуг, признаются расходами того отчетного периода, в котором признаны доходы от их предоставления. Этот принцип трудно совместить со страховыми выплатами, которые страховщик может осуществлять как в начале, так и в конце действия страхового договора, когда страховые премии или уже поступили, или еще должны поступить.

В связи со спецификой деятельности страховщиков и возникновением затрат, не присущих субъектам других сфер деятельности, считаем применения требований ПБУ 10/99 по формированию расходной части деятельности именно 
страховых компаний экономически неоправданным. Ведь указанный в нем состав расходов не по всем их видам присущ этим компаниям и не дает четкого и полного представления о структуре стоимости страховых услуг и других составляющих затрат. Поэтому актуализируется разработка и внедрения стандарта с предоставлением методических рекомендаций по учету расходов страховщиков, который должен учитывать особенности специфики работы этих субъектов рынка для формирования расходов.

Изучая проблемы формирования себестоимости страховых услуг и составления отчетности страховыми компаниями, стоит учесть, что принципы действующих ПБУ «Доходы» и «Расходы» не распространяются на данных субъектов рынка, а специализированного стандарта, который бы регламентировал данные аспекты учета, на сегодня не разработано. Поскольку на законодательном уровне определена обязательность составления финансовой отчетности для страховщиков по международным стандартам, логично предположить, что доходы и расходы также должны признаваться в соответствии с их требованиями. Однако если в международной системе учета признания доходов регламентирует МСФО 18 «Доход», то расходы признаются нормами отдельных стандартов учета. Для отражения операций в учете участниками страхового рынка применяются также нормы МСФО 4 «Договоры страхования» [6, с. 12].

Отчетность, составленная по международным стандартам, делает страховую компанию понятной и открытой для любого зарубежного сотрудничества. Однако процесс использования МСФО требует компетентной и серьезной организации. Отчетность страховщика, составленная по требованиям МСФО, отражает информацию, которая ранее раскрывалась в финансовой и специальной отчетности (отчетных данных) страховой компании.

Соответственно, встает необходимость разработки алгоритмов заполнения такой отчетности не только с методикой расчета показателей по данным аналитического учета, но и с отражением процесса их формирования по данным счетов синтетического учета. Очевидно, возникает необходимость разработки рекомен- 
дованного рабочего плана счетов страховой компании. По нашему мнению, существующий план счетов вполне может удовлетворить требования страховщиков при условии его детализации путем открытия субсчетов третьего порядка и создание нескольких новых специализированных субсчетов.

Таким образом, только при условии использования комплексного подхода к применению МСФО страховщиками отечественная система бухгалтерского учета сможет удовлетворить требования пользователей и обеспечить эффективный процесс формирования финансовой отчетности.

Российский страховой рынок постепенно синхронизируется с европейским. Исходя из западного опыта, российские страховые компании должны выполнить следующие операции для гармонизации стандартов учета:

- усовершенствовать внутренние процессы, чтобы легко получать необходимую аналитику для формирования отчетности;

- разработать правила для корректного отражения операций в автоматизированных системах учета;

- обеспечить достаточную гибкость систем учета, чтобы быстро реагировать на новые требования регулирующих и надзорных органов;

- найти способ получать и обрабатывать больше аналитических данных из страховой системы;

- вести параллельный учет.

\section{Список литературы}

1. Расходы организации: Положение по бухгалтерскому учету (ПБУ 10/99), приказ Минфина РФ от 06.05.1999 г., №33н (ред. от 06.04.2015).

2. Управление затратами и контроллинг: учеб. пособие / Е.Б. Никитина, С.Л. Жуковская. - Пермь: Перм. гос. нац. исслед. ун-т, 2019. - 129 с.

3. Экономика организации (предприятия): учебник / В.Д. Грибов, В.П. Грузинов, В.А. Кузьменко. - 10 е изд., стер. - М.: Кнорус, 2016. - 416 с.

4. Дмитриева И.М. Бухгалтерский учет и анализ: учебник для академического бакалавриата / И.М. Дмитриева, И.В. Захаров, О.Н. Калачева; под ред. И.М. Дмитриевой. - М.: Юрайт, 2018. - 358 с. 
5. Аверина К.М. Понятие себестоимости продукции / К.М. Аверина // Полиграфист. В помощь руководителю и главному бухгалтеру. - 2015. - №1. - С. 70.

6. Белгородцева М.А. Методика учета доходов и расходов в страховых компаниях: современное состояние и направления усовершенствования / М.А. Белгородцева // Синергия учета, анализа и аудита в обеспечении экономической безопасности бизнеса и государства: сборник материалов II Международной межвузовской научно-практической конференции, посвященной памяти проф. Петровой В.И. и проф. Баканова М.И. - 2016. - С. 10-19.

\section{References}

1. Raskhody organizatsii: Polozhenie po bukhgalterskomu uchetu (PBU 10.

2. Nikitina, E. B., \& Zhukovskaia, S. L. (2019). Upravlenie zatratami i kontrolling: ucheb. posobie., 129. Perm': Perm. gos. nats. issled. un-t.

3. Gribov, V. D., Gruzinov, V. P., \& Kuz'menko, V. A. (2016). Ekonomika organizatsii (predpriiatiia): uchebnik., 416. M.: Knorus.

4. Dmitrievoi, I. M., Dmitrieva, I. M., \& Zakharov, I. V. (2018). Bukhgalterskii uchet i analiz: uchebnik dlia akademicheskogo bakalavriata., 358. Kalacheva; M.: Iurait.

5. Averina, K. M. (2015). Poniatie sebestoimosti produktsii. Poligrafist. V pomoshch' rukovoditeliu i glavnomu bukhgalteru, 1, 70.

6. Belgorodtseva, M. A. (2016). Metodika ucheta dokhodov i raskhodov v strakhovykh kompaniiakh: sovremennoe sostoianie i napravleniia usovershenstvovaniia. Sinergiia ucheta, analiza i audita v obespechenii ekonomicheskoi bezopasnosti biznesa i gosudarstva: sbornik materialov II Mezhdunarodnoi mezhvuzovskoi nauchno-prakticheskoi konferentsii, posviashchennoi pamiati prof. Petrovoi V.I. i prof. Bakanova M.I, S. 10.

Лопата Петр Владимирович - студент, ФГБОУ ВО «Российский экономический университет им. Г.В. Плеханова», Москва, Россия

Lopata Petr Vladimirovich - student, Plekhanov Russian University of Economics, Moscow, Russia. 